\title{
NOTAS
}

\section{Consideraciones para una edición crítica de la Lira Popular}

\author{
Magdalena Vigneaux Ariztía ${ }^{1}$, Raïssa Kordic Riquelme ${ }^{2}$ \\ ${ }^{1}$ Universidad de Chile, Correo electrónico: magdalenavigneaux@gmail.com \\ ${ }^{2}$ Universidad de Chile, Correo electrónico: Raissa.kordic@gmail.com
}

Ya en el siglo XIX se despierta un interés por el estudio de la cultura y la literatura populares, pues los románticos veían en ellas la expresión del espíritu nacional. Sin embargo, no es hasta la segunda mitad del siglo XX que la cultura popular deja de percibirse como subcultura, o de ser considerada como exótica o marginal.

En Chile, el creciente interés por lo popular, quizá exaltado por los bicentenarios hispanoamericanos, se ha manifestado también en la cada vez más extendida atracción por la Lira Popular. Así, en los últimos años ha tenido lugar una serie de publicaciones en torno a ella, entre las que destacan los trabajos de Micaela Navarrete, Marcela Orellana y Simoné Malacchinni. No obstante, no existe mucha claridad respecto de las colecciones y ediciones con que se aborda este fenómeno literario. En este sentido, nuestro artículo pretende esclarecer qué se entiende por Lira Popular y cuáles son y en qué consisten las colecciones de pliegos de las que se dispone actualmente. Asimismo, hacer una breve revisión de las ediciones que se han hecho hasta el momento de hojas sueltas y proporcionar algunas consideraciones a tener en cuenta para un futuro trabajo en una edición crítica de la Lira Popular.

\section{Cómo Nace y Qué es la LiRa Popular}

A raíz del proceso de modernización y del nuevo escenario socioeconómico que emergió en el país hacia fines del siglo XIX, "se produjeron cambios importantes en la producción, circulación y consumo de bienes artísticos” (Subercaseaux 2011: 429). En este sentido, no solo se amplía y diversifica el mercado cultural, sino que también "se inicia una constelación cultural de tipo moderno, con circuitos culturales paralelos, de elite, de masas y popular” (Subercaseaux 2011: 429). Así, junto a la ópera de la aristocracia y los espectáculos de zarzuela de las capas medias, la lira se sitúa como un circuito claramente diferenciado de cultura popular.

La Lira Popular, por tanto, es un fenómeno urbano, estrechamente ligado a los procesos de migración campo-ciudad. Esta encuentra sus raíces en la poesía 
tradicional oral, propia del mundo campesino; sin embargo, como bien señala Marcela Orellana, "la lira era una forma nueva que no cabía en la poesía culta, pero tampoco en lo popular tradicional” (Orellana 2005: 13-14). En efecto, el paso de la oralidad a la escritura, que implicó adaptarse al nuevo contexto urbano, produjo una modificación en la poesía misma, ya que al existir un soporte menos efímero ya no es necesario que la poesía se limite a actuar como memoria colectiva.

El paso de la oralidad a la escritura supone, también, un nuevo público: lector desconocido, que le exige argumentos nuevos con respecto a los grandes tópicos tradicionales. El nuevo público urbano se interesa por nuevos asuntos que dicta el contexto urbano” (Orellana 2005: 19). Así, el poeta escribirá sobre el acontecer citadino, sobre lo cotidiano, lo que, además, provoca que vaya apareciendo una primera persona: "el contar sucesos reales y contemporáneos hace que se involucre poco a poco y gradualmente vaya tomando partido, dando opiniones e interpelando al lector a favor de su causa” (Orellana 2005: 57). El poeta ya no será la memoria del pueblo, que recrea historias y personajes a través del estilo indirecto, sino que asumirá una voz propia.

Como señala Bernardo Subercaseaux, si bien la lira fue socialmente invisible ${ }^{1}$, en el sentido de que circuló por vía oral o a través de pliegos sueltos y perecibles, se debe en gran parte a Rodolfo Lenz (1863-1938) que hoy se tenga información de ella, pues este estudioso alemán se dedicó durante cuatro años, desde 1890 hasta 1894, a recopilar pliegos en Santiago y sus alrededores. "El filólogo reunió cientos de hojas y además registró datos respecto de su circulación y el modo en que éstas eran voceadas y vendidas por los poetas” (Subercaseaux 2011: 457). Así, en su publicación Sobre la poesía popular impresa de Santiago de Chile (Lenz 1919), se encuentran datos que pueden resultar útiles para establecer las características de los pliegos mismos y de sus formas de difusión.

\section{DESCRIPCIÓN DE LOS DOCUMENTOS}

Cada una de las hojas de lira mide $38 \times 55$ cm aproximadamente; está ilustrada con grabados y clichés ${ }^{2}$ y tiene un promedio de seis composiciones en verso. Cada una de estas composiciones, a su vez, está formada por una cuarteta y cinco décimas espinelas ${ }^{3}$.

Las cuatro primeras décimas se cierran con el verso respectivo de la cuarteta. La quinta actúa como cierre de la composición. Sin embargo, en su forma oral, la

Si bien la lira pudo ser socialmente invisible en el sentido que lo plantea Subercaseaux, es decir, en el sentido de que circuló por vía oral o a través de pliegos sueltos y perecibles, no lo fue en el sentido de su notoriedad dentro de la sociedad de la época. Si la lira se vendía de manera más o menos clandestina, debe haber sido de sobra conocida, al menos por las clases populares, quienes se acercaban a comprar los pliegos.

Estampas antiguas que existen en las imprentas, hechas "para servir de ilustración a alguna novela, un almanaque o devocionario. Su variedad no deja nada que desear: paisajes, escenas de combates, buques de guerra, una doncella abandonada en la playa del mar, escudos de armas, flores, frutas, retratos de personas célebres de la actualidad o de tiempos pasados i cualesquiera otros, etc., etc. Mui a menudo la relación con los argumentos es superficial o nula" (Lenz 1919: 573-4).

3 Décima octosilábica con la distribución de las rimas abbaaccddc. El nombre se debe a su inventor Vicente Martínez Espinel (1550-1642). 
composición parece no abrirse con una cuarteta, sino con una (sexta) décima: "Como la melodía y el acompañamiento exijen la décima completa, los cuatro versos del tema se completan con seis versos más que constituyen una especie de exordio improvisado por el cantor, i que no se agrega cuando se imprime la poesía” (Lenz 1919: 529). Esto introduce, además, otra de las características de la lira, a saber: que se distingue entre el autor de los versos y la persona que los presenta al público cantándolos. En efecto, el autor es el poeta, pueta popular o versero y la persona que los presenta, el cantor o músico. No obstante, hay que tener presente que, debido a su carácter impreso, "en jeneral, estas hojas ya no son destinadas al canto, sino a la simple lectura” (Lenz 1919: 524).

Por último, resta decir que las hojas de poesía eran vendidas en lugares públicos como mercados y la estación de ferrocarril. "Los suplementeros que venden las hojas, gritan en voz alta estos títulos [sensacionalistas y llamativos], a veces precediendo su letanía por una introducción: «Vamos comprando, vamos pagando, vamos leyendo, vamos vendiendo...» sigue el título en voz monótona sin pausa hasta concluir la enumeración de las materias i se termina repitiendo en tono agudo: « iLos versos! ¡ Los versos!»” (Lenz 1919: 573). Aunque solo en contadas ocasiones estos suplementeros eran los mismos autores, era común que tanto unos como los otros hubiesen sido arrastrados por los procesos de migración campo-ciudad, lo que es reflejo de la crisis social que sucedió al auge económico proporcionado por el salitre 4 .

\subsection{Los pliegos 5}

La hoja de lira es una hoja de medio pliego que se presenta de manera extendida, impresa por una sola cara. Sin embargo, cuando se habla de medio pliego se alude solo al formato más característico de los pliegos, que corresponde al de $55 \times 38$ cm, pero también existen pliegos más pequeños y más grandes. Simoné Malacchinni (2015) hace un estudio detallado del formato de los pliegos a partir de la revisión de la totalidad de las hojas que componen las colecciones Rodolfo Lenz y Alamiro de Ávila, en el que determina que existen fundamentalmente seis formatos:

\footnotetext{
El llamado "periodo de oro" de la Lira Popular, que corresponde a la producción que va desde 1890 a 1910, coincide con algunos de los años más críticos de la "cuestión social" en Chile.

En "Poesía de cordel española y lira popular chilena: una lectura desde la materialidad y su apropiación popular", Rocío Rodríguez se hace cargo de la materialidad de los pliegos y de cómo estos le dan un carácter popular a esta poesía. "Tanto el de la lira como el de la poesía de cordel es un soporte que lleva inscrita la inestabilidad. Su carácter rudimentario, su apariencia sencilla, invita a un consumo rápido. Su preservación no se piensa como imperativa. Aquello de scripta manent más pareciera aplicable al libro propiamente tal, objeto que sí se registra como bien de lujo en testamentos y que se resguarda en una biblioteca. Para que el estudioso pueda acceder a los pliegos sueltos y hojas volantes, debe procurar configurar previamente un archivo. Es esta una literatura que, por su misma materialidad, requiere de cierta labor de recolección y acopio que no suele demandar el libro, al que las cubiertas y guardas parecen asegurarle más años de vida. Y es este, claro está, un índice de su condición popular. Como explica Trevor Dadson, '[l]os libros más populares, los que se leen más, son también los que acaban en un estado peor, o son prestados, o se pierden porque se utilizan más frecuentemente y se cambian de su sitio habitual en las estanterías, mientras que los libros de devoción o un tomo in-folio de historia o de literatura sagrada se consultan menos a menudo y conservan una condición más impecable’ (126). En otras palabras, la popularidad de los textos los hace también móviles y pasajeros. Pero, además, su formato facilita dicha transitoriedad. El círculo deviene vicioso: de dimensiones fácilmente transportables, como literatura portátil, se propagan mano a mano y boca a boca. La itinerancia colectiva emerge así desde las señas materiales de identidad” (Rodríguez 2014: 141-143).
} 
- Pliegos verticales

Formato grande: $76,5 \times 54,5 \mathrm{~cm}$

Formato regular: $55 \times 38 \mathrm{~cm}$

Formato pequeño: $38 \times 27,5 \mathrm{~cm}$

- Pliegos horizontales

Formato grande: $55 \times 77 \mathrm{~cm}$

Formato regular: $38 \times 55 \mathrm{~cm}$

Formato pequeño: $27,5 \times 38 \mathrm{~cm}$

El 78,35\% de los pliegos de estas colecciones adopta el formato regular en disposición vertical, que es el que se considera más característico de la Lira Popular. La medida del formato regular, como señala Malacchinni, corresponde a 1/4 del "formato mercurio" $(110 \times 77 \mathrm{~cm})$, del que también se desprendería el tamaño del pliego pequeño, pues 1/8 de mercurio corresponde a $38 \times 27,5 \mathrm{~cm}$.

Lenz señala que las hojas sueltas están impresas en "papel ordinario blanco" (1919: 571). Probablemente, se trata del mismo tipo de papel que las imprentas usaban para imprimir los libros 6 . El papel no presenta filigranas. "Con respecto a la impresión, no presenta marcas de plancha o tipo, probablemente porque después de ser impreso el pliego fue secado en una prensa, siendo éste el momento en que la marca de plancha desaparece” (Jara y López 2004: 74).

Respecto de la tinta, Jara y López sostienen que se trataría de tinta tipográfica, por la penetración no profunda de esta. En cuanto al color, la mayoría de los pliegos se encuentran impresos en tinta negra, pero hay algunos impresos en tintas de colores, como morada, verde, azul, roja y naranja. "Cabe mencionar que existen pliegos con más de un color, lo que supondría dos 'pasadas' de impresión; incluso hay alguno que habría jugado con la superposición de los colores, derechamente sobreimpresión, técnicas que nos hablan de cierto nivel de conocimiento sobre la impresión" (Malacchinni 2015: 151). La doble pasada de impresión también se evidencia en el descalce entre el lado derecho e izquierdo, o superior e inferior.

En relación con la imagen de los pliegos, la mayoría corresponde a grabados xilográficos. "En una segunda jerarquía están los grabados en metal o clichés. Finalmente, en pliegos posteriores, se incorporará con mayor frecuencia el uso de fotograbado” (Malacchinni 2015: 111). Así como a lo largo de la historia de la Lira Popular se incorporan nuevos recursos gráficos, como es el caso del fotograbado, también se observan cambios en aspectos como el formato ${ }^{7}$ y los titulares ${ }^{8}$ de los pliegos.

\footnotetext{
A partir del análisis de los pie de imprenta de los pliegos, Simoné Malacchinni plantea que la Lira no habría sido un fenómeno marginal, como comúnmente se piensa, puesto que fueron impresas en algunas de las más grandes e importantes imprentas de la época.

7 "En cuanto al formato, se podría decir en términos generales que los pliegos en un inicio habrían sido de formato horizontal pequeño $(27,5 \times 38 \mathrm{~cm})$ para luego agrandarse y estabilizarse cerca del formato vertical regular $(55 \times 38 \mathrm{~cm})$. Este último es el más utilizado encontrándose en mayor cantidad precisamente entre 1894 y 1903, años que habrían sido muy prolíficos para la producción de pliegos. Finalmente, el formato habría vuelto a disminuir, esta vez manteniendo la disposición vertical de la hoja y asumiendo rasgos similares a cancioneros o a la misma prensa" (Malacchinni 2015: 156-157).

$8 \quad$ "En cuanto al uso del titular, se puede decir que en los pliegos del último período, el tamaño preponderante se reserva para el nombre de la hoja (como Lira Chilena o Versos Populares) en desmedro del titular 'chillón', centrándose por tanto en la identificación misma de la hoja según la propuesta de cada autor [...]” (Malacchinni 2015: 157).
} 
Los pliegos constan de una imagen o grabado y un texto conformado por 4 a 7 composiciones en versos, más la firma del autor (aunque en algunos casos las décimas son anónimas) y el pie de imprenta (no en la totalidad de los pliegos, pero sí en más del 50\% de los casos). Respecto de la diagramación, la proporción texto/imagen y la tipografía de los pliegos, Simoné Malacchinni (2015) hace un completo análisis en su reciente libro Lira popular. Identidad gráfica de un medio impreso chileno.

\section{Colecciones de la Lira Popular}

Actualmente, hay tres colecciones de lira popular: la Colección Rodolfo Lenz, la Colección Alamiro de Ávila y la Colección Lira Popular de la Universidad de Chile. Las dos primeras se encuentran en el Archivo de Literatura Oral y Tradiciones Populares de la Biblioteca Nacional y la tercera está custodiada por el Archivo Central Andrés Bello de la Universidad de Chile. Estas tres colecciones constituyen un corpus de alrededor de mil quinientos documentos ${ }^{9}$.

La Colección Rodolfo Lenz contiene 327 pliegos, producidos entre 1870 y 1940, aproximadamente; es la colección que abarca el marco temporal más amplio. Esta colección fue donada por Rodolfo Lenz el 15 de mayo de 1933 a la Biblioteca Nacional, cuyo director era el presbítero Alejandro Vicuña, y quedó ubicada en la Sección Chilena a cargo del escritor y folklorista Raúl Silva Castro. El hecho de que la colección cuente con pliegos posteriores a 1933 revela que existieron nuevos ingresos después de la fecha de la donación. Además, de acuerdo a investigaciones sobre Lenz escritas en la década de 1960, esta colección habría contado con cerca de 500 ejemplares, de lo que se deduce que muchas hojas de lira se han perdido.

En 1988, la Colección Rodolfo Lenz fue microfilmada y Sandra Acevedo realizó fichas de información. Desde fines de la década de 1990, la colección se almacena en el Archivo de Literatura Oral y Tradiciones Populares de la Biblioteca Nacional.

Los pliegos de la Colección Rodolfo Lenz se encuentran separados en nueve volúmenes. Los volúmenes son un conjunto de documentos empastados que tienen un número identificador. No obstante, el volumen 5 corresponde a una caja de conservación que contiene los documentos almacenados individualmente en carpetas de conservación. Además, los pliegos de esta colección están pegados sobre un segundo soporte de cartulina, que es en el que está la costura de la encuadernación en la mayoría de los pliegos.

La Colección Alamiro de Ávila está conformada por 349 documentos, producidos entre los años 1890 y 1910, aproximadamente, período que se considera como la época de oro de la lira popular. Esta colección es la que se adquirió más recientemente, pues fue comprada en 1998 por la Biblioteca Nacional a Washington Pereira, un librero uruguayo radicado en Argentina, quien la había comprado en 1993 a la esposa de Alamiro de Ávila, después de la muerte de este.

Los pliegos de poesía popular estaban almacenados en una encuadernación tipo álbum, dividido en 8 volúmenes ${ }^{10}$. En el lomo presentaban etiquetas con números de

Como se trata de colecciones cerradas, el número de pliegos debería mantenerse estable.

Nueve según en Gouet y Caviares, quienes estuvieron a cargo del proceso de restauración y conservación de los pliegos de esta colección. 
catalogación y en su interior y en los pliegos existían diversos códigos. Prácticamente la totalidad de ellos se encontraba laminado con un segundo soporte realizado en tela, lo que permitió su conservación.

Al poco tiempo de ser recibida en la Biblioteca Nacional, a la colección se le asignó un nuevo número de catalogación (correlativo) ubicado en la zona inferior central del pliego, se microfilmó y se realizaron las fichas de información. Posteriormente, las fichas fueron revisadas y los pliegos medidos por Rodrigo Invernizzi.

Los volúmenes fueron almacenados en la oficina de la jefa del Archivo de Literatura Oral y Tradiciones Populares hasta el año 2003, fecha en que la colección fue sometida a un proceso de conservación y restauración en el marco de un proyecto de titulación para la carrera de Historia del Arte realizado por Andrea Jara Gouet y Catherine López Caviares. Los pliegos fueron almacenados individualmente en carpetas de conservación contenidas en 10 cajas. Las cajas de conservación se encuentran ubicadas en la sala de colecciones del ALOTP ${ }^{11}$ (Biblioteca Nacional 2009a: 3).

La Colección Lira Popular de la Universidad de Chile, más conocida como Colección Raúl Amunátegui, que es el nombre con que antiguamente se identificaba, es la que cuenta con el mayor número de pliegos: 880, producidos entre los años 1886 y 1930, aproximadamente. Se desconoce la fecha exacta en que el Archivo Andrés Bello adquirió esta colección, no obstante, se sabe que ya en la década de 1970 este grupo documental formaba parte de su acervo, pues Alamiro de Ávila -ex director de la Biblioteca Central de la Universidad de Chile, antecedente del actual archivo- lo menciona en el Catálogo de la "IV Bienal Americana de Grabado", realizada en 1970 en el Museo Nacional de Bellas Artes.

Originalmente, los pliegos de esta colección estaban encuadernados en tres volúmenes; sin embargo, en el proceso de conservación, se desarmaron estos volúmenes y se hicieron carpetas individuales. Estas carpetas están guardadas en varias cajas de conservación.

La Colección Lira Popular, además de ser la de mayor volumen, es la que cuenta reunidos entre sus pliegos con la más amplia presencia de poetas que publicaron en este formato. En efecto, el Archivo Andrés Bello resguarda la producción de 88 poetas, mientras que las colecciones Rodolfo Lenz y Alamiro de Ávila cuentan con la de 55 y 42 poetas, respectivamente. En este sentido, esta colección en particular es clave para estudiar la diversidad de este fenómeno cultural.

\section{Ediciones de la Lira Popular}

Las tres colecciones de la Lira Popular están digitalizadas y disponibles en la web, lo que permite trabajar con mayor facilidad que con el formato de microficha, con el que se trabajaba hasta hace muy poco. Sin embargo, no existen ediciones impresas que se hayan hecho cargo de recoger lo más fidedignamente posible los pliegos sueltos. Quizás lo más cercano a ello sea La Lira Popular. Poesía popular impresa del siglo XIX (1999), una pequeña selección de pliegos de la Colección

Archivo de Literatura Oral y Tradiciones Populares. 
Alamiro de Ávila ${ }^{12}$, que Micaela Navarrete editó con motivo de la Feria Internacional del Libro de Guadalajara.

Micaela Navarrete ha hecho cuatro compilaciones de las décimas de algunos poetas populares: Aunque no soy literaria: Rosa Araneda en la poesía popular del siglo XIX (1998), Por historia y travesura: la lira popular del poeta Juan Bautista Peralta (2006), Los diablos son los mortales: la obra del poeta popular Daniel Meneses (2008) y Si a tanta altura te subes: 'contrapunto' entre los poetas populares Nicasio García y Adolfo Reyes (2011). Estas compilaciones, además de ser un intento por rescatar a ciertas figuras, tratan de recuperar el fenómeno de la Lira Popular. No obstante, al menos respecto de este último objetivo, el trabajo presenta bastantes deficiencias.

En primer lugar, Micaela Navarrete no establece ningún criterio de edición aparte del de conservar la ortografía: "Los versos fueron transcritos tal cual fueron impresos en su época, conservando su ortografía y en algunos casos los grabados populares que las [sic] ilustraban" Navarrete 1998: 26). Ni siquiera se establece el significado de las abreviaturas que utiliza para citar los pliegos, como es el caso de mic. o Col. Am., para referirse a microficha y a la Colección Amunátegui, respectivamente ${ }^{13}$.

En segundo lugar, y en relación con los grabados mencionados en la cita del párrafo anterior, muchas veces estos se ponen junto a composiciones poéticas con las que no estaban relacionados originalmente. Si bien en las compilaciones de Navarrete se busca que exista una relación entre las imágenes y al menos uno de los poemas de la página en que se encuentran, este vínculo es establecido artificialmente por Navarrete y quienes colaboraron en la edición y no necesariamente corresponde a un nexo ya presente en los pliegos. También es importante destacar que en algunas ocasiones los grabados son modificados, pues, por ejemplo, se invierte el sentido hacia el que se dirige la imagen. Aunque esto se puede relacionar con un rasgo propio de la Lira, que es el de las imágenes 'espejadas'14, probablemente Navarrete no lo hizo con la intención de reflejar este aspecto, sino simplemente para hacer coincidir el contenido de los versos con el grabado que los ilustra.

En tercer lugar, Navarrete agrupa los versos por temas, pero no hay en el prólogo ni en ningún otro lugar una justificación para esta clasificación temática. Los temas, como "amor", "literatura", "crímenes, salteos, desgracias", "fusilamientos", parecen ser subjetivos, pues no se anclan a algún criterio que tenga que ver específicamente con la poesía popular, como podrían ser los llamados "fundamentos". En efecto, un fundamento es un tema tradicional de la poesía popular, que va asociado a determinado léxico y a fórmulas recurrentes, como también a ciertos ritmos musicales, lo que sobrepasa la composición poética misma.

Son solo 17 pliegos de esa única colección, por lo que no se hace cargo del fenómeno en su totalidad.

13 Como se puede desprender de estas abreviaturas, las referencias bibliográficas de las ediciones de Micaela Navarrete están desactualizadas. Llegar a los pliegos de los que se extraen las composiciones poéticas supone un problema para el lector, pues la numeración de las microfichas no es correlativa a la de formato digital.

14 Como señala Malacchinni, "hay casos en que se observa la misma xilografía, pero completamente "espejada": probablemente se trataría de una copia de la imagen a partir del resultado impreso y no desde el taco xilográfico original. Otra alternativa se referiría a una copia directa de la xilografía por medio de un cliché, dando como resultado la imagen impresa al revés" (2015: 126). En otras oportunidades, se producen dos tacos xilográficos con una imagen prácticamente idéntica. 
En cuarto lugar, tal vez por el mismo hecho de que los versos estén agrupados por tema, es difícil ver la relación entre las composiciones poéticas de un mismo pliego ${ }^{15}$. Si bien bajo cada una de las composiciones reproducidas se encuentra la referencia al pliego del que fue extraída, no es fácil visualizar el pliego en su conjunto, sobre todo por la dificultad que supone llegar a la hoja de lira a través de la referencia. En este sentido, se pierde un aspecto de la Lira Popular que también es significativo, que es el que el poeta decida reunir esas composiciones en una misma hoja.

Por último, en el tamaño de estos libros de Navarrete parece estar la intención de aproximarse al tamaño de los pliegos, al menos a los de formato más pequeño, sin embargo, este no corresponde al original en absoluto. Una posibilidad aceptable sería usar algún tipo de escala que permitiera hacerse una idea de las dimensiones de los pliegos que se reproducen, pero no hay nada de esto evidenciado en el trabajo de Navarrete.

\section{LA EDICIÓN CRÍTICA}

A modo de cierre, podemos afirmar que está pendiente la tarea de una edición crítica de la Lira Popular, que recoja este fenómeno lo más fielmente posible y lo explique al lector actual, tanto en sus referencias históricas como en las literarias y folklóricas. Paralelamente, habría que anotar las voces que puedan ser enigmáticas o confusas para nuestra cultura urbana y presente siglo.

Uno de los aspectos más arduos, pero indispensable, sería la comparación folio a folio de las tres colecciones: ¿qué relación hay entre ellas tanto estructuralmente como desde el punto de vista de la composición y contenido?, ¿eran los mismos poetas los autores que publicaron por diversas vías?, etc.

Así como en la actualidad el diario La Cuarta ha sido consignado como fuente de invenciones léxicas a la vez que rescatador de las tradicionales populares: ¿cumplía una función cultural similar la Lira en su época?

Un trabajo de este tipo, llevado a cabo con rigurosidad, constituiría la base confiable de posteriores estudios sobre la poesía y cultura populares chilenas, y evitaría caer en errores de interpretación a los que inducen las ediciones descuidadas.

\section{OBRAS CITADAS}

Archivo Central Andrés Bello. 2015. Registro Guía Colección Lira Popular. Biblioteca Nacional. 2009a. Guía de Fondo Colección Alamiro de Ávila.

\footnotetext{
Rocío Rodríguez, en una nota al pie de su artículo "Poesía de cordel española y lira popular chilena: una lectura desde la materialidad y su apropiación popular", también señala este problema: "Por ello, y a pesar de su gran utilidad y valor, me parecen arriesgadas las formas en las que se ha editado en el presente la lira popular en Chile. Si bien el criterio autorial es el que predomina en las diferentes publicaciones de la DIBAM, se ha roto la organización interna del pliego al presentar de modo independiente los poemas, de acuerdo con una ordenación temática. La captación de la narración interna de la hoja volante y el diálogo que establece con grabados y titulares se ve entonces obstaculizada. En contraste, óptimas me parecen las ediciones facsimilares de pliegos sueltos aparecidas en la colección Joyas Bibliográficas, aun con las dificultades que pueden suponer para el lector moderno" (Rodríguez 2014: 145). Rodríguez, quien trabaja desde una perspectiva transatlántica, compara las ediciones de la Lira con las facsimilares que Joyas Bibliográficas ha publicado de la poesía de cordel española.
} 
2009b. Guía de Fondo Colección Rodolfo Lenz.

Jara, Andrea y Katherine López. 2004. Conservación y restauración de Alamiro de Ávila de la Lira Popular. Memoria para optar al título de Historiador del Arte; Santiago, Universidad Internacional SEK, Facultad de Estudios del Patrimonio, Carrera Historia del Arte.

Lenz, Rodolfo. 1919. Sobre la poesía popular impresa de Santiago de Chile. Santiago: Impr Universo.

Malacchinni, Simoné. 2015. Lira Popular. Identidad gráfica de un medio impreso chileno. Santiago: Ocho Libros Editores.

Navarrete, Micaela. 1998. Aunque no soy literaria: Rosa Araneda en la poesía popular del siglo XIX. Santiago: Archivo de Literatura Oral y Tradiciones Populares.

. 1999. La Lira Popular. Poesía popular impresa del siglo XIX. Santiago: Archivo de Literatura Oral y Tradiciones Populares; Universitaria; DIBAM, Departamento de Extensión Cultural.

2006. Por historia y travesura: la lira popular del poeta Juan Bautista Peralta. Santiago: Eds. de la Dirección de Bibliotecas, Archivos y Museos; Archivo de Literatura Oral y Tradiciones Populares; Centro de Investigaciones Diego Barros Arana.

. 2008. Los diablos son los mortales: la obra del poeta popular Daniel Meneses. Santiago: Eds. de la Dirección de Bibliotecas, Archivos y Museos; Archivo de Literatura Oral y Tradiciones Populares; Centro de Investigaciones Diego Barros Arana.

. 2011. Si a tanta altura te subes: 'contrapunto' entre los poetas populares Nicasio García y Adolfo Reyes. Santiago: Archivo de Literatura Oral y Tradiciones Populares, Centro de Investigación Diego Barros Arana, Gobierno de Chile.

Orellana, Marcela. 2005. Lira popular. Pueblo, poesía y ciudad en Chile (1860-1976). Santiago: Universidad de Santiago de Chile.

Rodríguez, Rocío. 2014. "Poesía de cordel española y lira popular chilena: una lectura desde la materialidad y su apropiación popular”. Revista de Humanidades 30: 129-165.

Subercaseaux, Bernardo. 2011. Historia de las ideas y de la cultura en Chile. Vol. I. Santiago: Universitaria. 
